Laboratorio de Arte, 7-1994 http://dx.doi.org/10.12795/LA.1994.i07.20

\title{
EL ARCHIVO DE PROTOCOLOS COMO BASE PARA LA ELABORACIÓN DE UNA HISTORIA DE MENTALIDADES: SEIS INVENTARIOS DE BIENES PERTENECIENTES A LA NOBLEZA SEVILLANA (1721-1731)
}

\author{
POR ANA MENDIOROZ LaCAMBRa
}

Los Archivos de Protocolos Notariales, albergan en sus fondos retazos de historia concluyentes a la hora de plantear trabajos de investigación, encaminados a dilucidar sobre las interrelaciones socio-políticas, culturales y económicas, responsables en última instancia de los comportamientos colectivos de cualquier comunidad.

Cada vez son más los trabajos que basados en documentación notarial, aportan nuevos datos para la concreción de una Historia de las Mentalidades; noticias que desde el punto de vista económico, político, o socio-cultural, aportan nuevas coordenadas para la investigación histórica de cualquier época.

Así pues, cuanto más claro y preciso sea el conocimiento acerca del momento histórico en estudio, tanto más fieles serán las conclusiones que obtengamos finalmente ${ }^{1}$.

Los Inventarios de Bienes, documentación extraída principalmente de los Archivos de Protocolos Notariales, son documentos que por su exhaustiva información, han servido de base referencial para trabajos de investigación de muy diferente índole ; no sólo en los referentes a contenidos socio-culturales, como cabría esperar, sino incluso en aquellos que tienen el campo económico como punto de reflexión ${ }^{2}$.

1. GOMEZ NAVARRO,Soledad: La documentación notarial y su utilización en el estudio de la muerte y la religiosidad: los testamentos por "abientestados" en Córdoba durante la segunda mitad del siglo XVIII" Archivo Hispalense ${ }^{\circ} 210,1986$ pag.49-62.

2. ALVAREZ SANTALO,L.C y GARCIA BAQUERO,A: Los inventarios post-mortem como fuente para la historia agraria del Antiguo Régimen". Actas II Coloquio de Historia de Andalucía l. Córdoba 1983 pag.137-149. 
Tras cuatro años de trabajo en el Archivo Histórico de Protocolos de Sevilla, periodo en el que realicé mi memoria de licenciatura ahora publicada por una editorial sevillana con el título genérico de "Fuentes para la historia del arte andaluz, noticias de arquitectura 1720-1740", cuento en mi haber con más de 100 inventarios de bienes, correspondientes al primer tercio de esta centuria; documentación sobre la que actualmente estoy trabajando, y de la que he entresacado el material para la confección de este artículo.

La obligación moral y social de testar en estas fechas que nos ocupan, ya ha sido puesta de manifiesto por autores españoles y extranjeros de reconocido prestigio $^{3}$, falta no obstante, un estudio en profundidad sobre otro documento ,que frecuentemente acompaña al testamento, en el que se describen exhaustivamente los bienes del difunto. No sólo en estos casos de fallecimiento es cuando se redacta esta documentación, también en vida del promotor suele realizarse este tipo de escritura notarial, siempre y cuando la situación personal del interesado lo reclame, caso harto frecuente son las deudas contraídas con terceros, o el simple reparto de bienes entre sus familiares más próximos.

Se trata como ya he referido anteriormente, de documentos de gran interés histórico y, no solamente por su contenido material, es decir relación detallada de las posesiones de un individuo, sino fundamentalmente, por esa lectura menos positivista,y sin duda más interesante, cargada de un mensaje histórico, revelador de los gustos, tendencias, actitudes y motivaciones imperantes en una colectividad; en suma, hitos cargados de una lectura social, necesaria para el auténtico conocimiento de la época. Para tener una idea clara del valor documental del inventario de bienes, antes deberemos contestar a preguntas como: cuándo, por quién, y para qué se protocoliza esta información.

En esta ocasión, no es nuestra pretensión el plantear un estudio riguroso del tema, ni mucho menos un análisis preciso y concluyente como respuesta a estas preguntas, sino más bien lo que pretendemos es el aportar unos testimonios reales y objetivos, que ilustren la idea temática y posteriormente susciten un estudio serio, y en suma concluyente sobre la información recogida en los inventarios de bienes.

La estructura interna de estos documentos, es similar en la mayoría de los casos recopilados, variando, claro está, lo referente a las claúsulas descriptivas del patrimonio referido en cada caso. Comienza la redacción, como en el resto de documentos notariales, con la ubicación física del hecho a desarrollar citando

3. No es mi intención el aportar bibliografía sobre este tema, por lo que remito a los lectores al artículo publicado por Soledad Gómez Navarro, mencionado en la nota 1. en el que se recrea en el aporte de documentación precisa sobre el tema. Quizás, sería interesante por lo que atañe a este tema, hacer hincapié en el libro de MALDONADO FERNENDEZ DEL TORCO,J: Herencias en favor del alma en el derecho español, Madrid,1944, también mencionado por la autora Gómez Navarro. 
el lugar en el que se realiza, con una mención del finado y de la persona que encarga el documento, indicando sus relaciones de parentesco, así como el motivo por el que se efectua. Posteriormente, se describen de manera precisa y exhaustiva todos los bienes muebles e inmuebles, para concluír con la firma de los otorgantes, testigos y del notario ejecutor legal del papel. No es muy frecuente la tasación de los objetos si no es en ocasiones puntuales, como es el caso de contracción de deudas importantes con terceros, en el que la relación exhaustiva de los bienes, convenientemente valorados por maestro perito en cada caso, sirve para saldar estos débitos.

Hemos elegido en esta ocasión, seis inventarios de bienes, fechados entre 1721 y 1731. Todos ellos correspondientes al estamento nobiliario de la ciudad y harto elocuentes por su contenido.

El día 23 de Mayo de 1721, Beatriz Francisca Dávila Aguirre y Contreras, viuda de Juan de Torres y la Vega Ponce de Leon, conde de Miraflores, efectua el inventario de los bienes tras la muerte de su esposo. Esta inventaría, la realiza frente al cúmulo de acreedores que le ha dejado su marido ${ }^{4}$.

Tres años más tarde, otro componente de esta misma familia, Francisco de Torres y la Vega Ponce de Leon, efectua el inventario de bienes tras la muerte de su padre Diego Torres y la Vega Ponce de Leon, conde de Miraflores, fallecido el 13 de Octubre de 1724. El inventario de sus pertenencias, como es habitual tras el fallecimiento, se efectua inmediatamente posterior al hecho y en este caso concreto, a partir del día 16 de Diciembre de ese mismo año, y hasta el día 15 de Enero de 1725. Sin duda de mayor cuantía que el anterior ${ }^{5}$, destaca primordialmente la colección de obras de arte, con más de doscientos cuadros que por su interés, son descritos con todo lujo de detalle, indicando la medida, el tipo de soporte y el tema ilustrativo de cada uno de ellos; es por esto que nos constan como pertenecientes a esta colección, un Tiziano y otro del Divino Morales.

Tras la muerte de Gerónimo Ortiz de Sandoval y Zúñiga, conde de Mejorada, su sobrino y yerno Luis Ortiz de Sandoval, efectua su inventario de bienes con fecha de 17 de Septiembre de $1721^{6}$.

Los albaceas del marqués de Villaverde, Lorenzo Pablo de Eceiza, realizan el inventario de la hacienda de campo de su propiedad, sita en el término municipal de Utrera, como paso previo a la repartición de sus bienes entre sus hijos María

4. Ver Apéndice documental. Documento 1.

5. Ver Apéndice documental. Documento 2.

6. Ver Apéndice documental. Documento 3. 
Teresa, Alonso y su mujer Luisa de Saavedra y Zenón, casada en segundas nupcias con Lorenzo de Arias Saavedra, marqués de Ribas. Es interesante la descripción sobre su hacienda de campo "La Concepción" 7, de la que forma parte relevante un oratorio, equipado por una amplia partida de obras de arte .

Finalmente, aportamos los dos inventarios de bienes realizados por los albaceas testamentarios de Ana Tello de Guzmán, viuda de Lorenzo Dávila y Medina, su primo, conde de Valdermoso. El documento, está fechado por su hermano Juan Dávila, de la Cía. de Jesús, con fecha de 2 de Julio de 1727, tras el fallecimiento de la condesa, el día 24 de Junio de ese mismo año. Aportamos también, una segunda declaración de sus bienes, varios años después, en $1731^{8}$, interesante por la relación de bienes vendidos y el valor obtenido por cada uno de ellos.

7. Ver Apéndice documental. Documento 4.

8. Ver Apéndice documental. Documentos 5 y 6 


\section{APÉNDICE DOCUMENTAL}

Debido a la extensión de estos documentos y pretendiendo una lectura lo más cómoda posible de los mismos, he optado no por la transcripción fiel del documento, sino por la presentación del mismo con una ortografía actual.

Documento 1.

Inventario de los bienes de Juan de Torres y la Vega Ponce de León, por su viuda Beatriz Francisca Dávila Aguirre Contreras con fecha de 23 de Mayo de 1721.

\begin{tabular}{|c|c|}
\hline \\
\hline 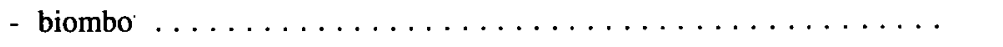 & $120 \mathrm{r}$. \\
\hline$\ldots \ldots \ldots \ldots \ldots \ldots \ldots \ldots \ldots \ldots$ & $4878 \mathrm{r}$. \\
\hline 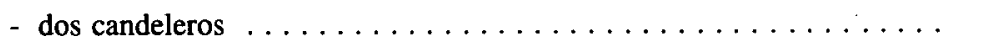 & $340 \mathrm{r}$. \\
\hline 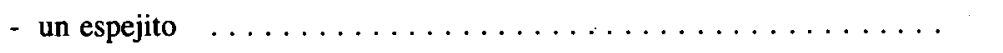 & 45 \\
\hline 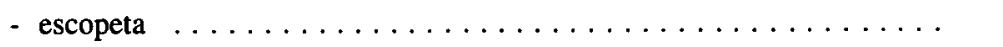 & $52 \mathrm{r}$. \\
\hline ornamentos de decir misa $\ldots \ldots \ldots \ldots \ldots \ldots \ldots \ldots$ & $180 \mathrm{r}$. \\
\hline dos mulas $\ldots \ldots \ldots \ldots \ldots \ldots \ldots \ldots \ldots \ldots \ldots$ & 50 \\
\hline una cortina de tafetán $\ldots \ldots \ldots \ldots \ldots \ldots \ldots \ldots$ & 75 \\
\hline pulseras de perlas $\ldots \ldots \ldots \ldots \ldots \ldots \ldots \ldots \ldots \ldots \ldots$ & $2250 \mathrm{r}$ \\
\hline seis platillos de plata $\ldots \ldots \ldots \ldots \ldots \ldots \ldots \ldots \ldots$ & 1500 \\
\hline cinco varas de paño $\ldots \ldots \ldots \ldots \ldots \ldots \ldots \ldots \ldots$ & \\
\hline hornillo de cobre $\ldots \ldots \ldots \ldots \ldots \ldots \ldots \ldots \ldots \ldots \ldots$ & 60 \\
\hline un reloj de León en bronce $\ldots \ldots \ldots \ldots \ldots \ldots \ldots \ldots$ & 285 \\
\hline caja con cuchillos de plata de hechura de águilas $\ldots \ldots \ldots \ldots \ldots$ & 90 \\
\hline bufete redondo $\ldots \ldots \ldots \ldots \ldots \ldots \ldots \ldots \ldots \ldots \ldots$ & \\
\hline 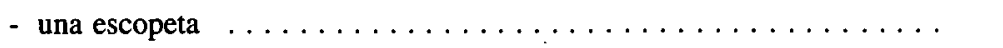 & \\
\hline$\ldots \ldots \ldots \ldots \ldots \ldots \ldots \ldots \ldots \ldots$ & 60 \\
\hline$\ldots \ldots \ldots \ldots \ldots \ldots \ldots \ldots \ldots$ & 180 \\
\hline cajita de ostiario $\ldots \ldots \ldots \ldots \ldots \ldots \ldots \ldots \ldots \ldots$ & \\
\hline escribanía pequeña de ébano y marfil $\ldots \ldots \ldots \ldots \ldots \ldots \ldots$ & \\
\hline 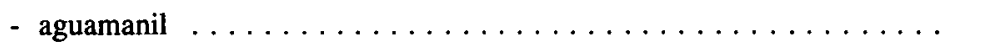 & 1 \\
\hline 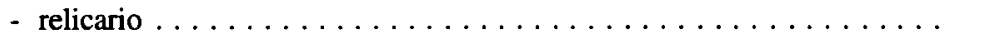 & \\
\hline 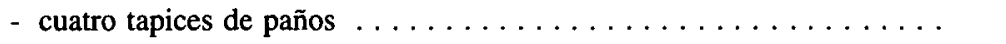 & 11 \\
\hline - espadín con puño de plata $\ldots \ldots \ldots \ldots \ldots \ldots \ldots \ldots \ldots \ldots \ldots \ldots \ldots \ldots$ & 240 \\
\hline - un carro de plata dorado $\ldots \ldots \ldots \ldots \ldots \ldots \ldots \ldots \ldots$ & \\
\hline - calzones de paño $\ldots \ldots \ldots \ldots$. & \\
\hline velón pequeño de azofar & \\
\hline$\because$ & \\
\hline 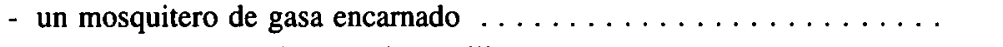 & \\
\hline & \\
\hline
\end{tabular}

- dos cortinas, sobremesa de cañamazo una colcha verde de estambre . 
- seis mercalines de plata hechura de conchas

- escribanía de plata

- un peinador de encajes

- almohadas de estrado

- siete láminas de cobre pequeñas echadas

- un lienzo de una vara de San Francisco de Paula

$100 \mathrm{r}$.

- un tabernáculo con sus puertas pintadas de Sta. María . . . . . . . . . .

$260 \mathrm{r}$.

- una alfombra . . . . . . . . . . . . . . . . . . . .

$240 \mathrm{r}$.

- cinco cortinas de caoba pequeñas $\ldots \ldots \ldots \ldots \ldots \ldots \ldots \ldots$

$52 \mathrm{r}$.

- (trastos de cocina)

$322 \mathrm{r}$.

- una pieza de raso de China

- dos cabezas de pintura de Jesús y María

- cinco varas de paño fíno $\ldots \ldots \ldots \ldots \ldots \ldots \ldots \ldots \ldots \ldots$

- tapicería de Bruselas

- velos de faldriquera

$350 \mathrm{r}$.

- imagen de marfil y cristal . . . . . . . . . . . . . . . . $1540 \mathrm{r}$

- un reloj grande de música . . . . . . . . . . . . . . . . . $1125 \mathrm{r}$.

- un reloj grande de campana . . . . . . . . . . . . . . . . . $810 \mathrm{r}$

- botones de plata de martillo ................... $168 \mathrm{r}$.

- varias láminas de cobre . . . . . . . . . . . . . . . . 65 r.

- lámina de fábulas ....................... $120 \mathrm{r}$.

- lámina en piedra de la Magdalena . . . . . . . . . . . . . $100 \mathrm{r}$.

- Ntra. Señora, Niño y San Juan . . . . . . . . . . . . . . . . . . 180 r.

- vidriera de Crucificado ..................... $90 \mathrm{r}$.

- pintura en lienzo de Ntra. Señora . . . . . . . . . . . . . $90 \mathrm{r}$.

- pintura de Ntra. Señora en tafetán . . . . . . . . . . .

- San Juan en lienzo . . . . . . . . . . . . . . . . . . . $30 \mathrm{r}$.

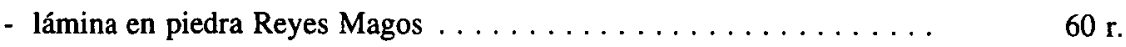

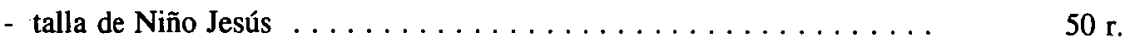

- San Fernando a caballo en marfil .................. 60 r.

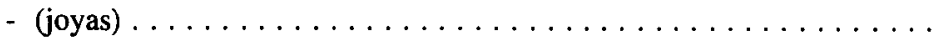

A.P.N.S. Ofc. 1 año 1721 fol. $498 \mathrm{r}-510 v$

\section{Documento 2.}

Inventario de los bienes del conde de Miraflores. 16 de Diciembre de 1724 hasta el 15 de Enero de 1725.

- escritorio con varios miles de escudos de plata.

- un escaparate y escritorio del Japón con pesos. 
- arcón con monedas de plata y medallones con imágenes de emperadores.

- diez candeleros viejos de plata.

- una salvilla grande y dos pequeñas.

- doce vasos de plata.

- tres jarrones grandes de plata.

- una fuente grande.

- una palangana.

- dos fuentes sobredoradas y tres grandes de plata.

- tres velones de plata de diferentes tamaños y hechura.

- dos varitas medianas y un tintero pequeño.

- unas espabiladeras con su platillo y cadenita.

- un cucharón grande y un salero mediano de plata.

- treinta y cinco cucharas y cinco tenedores.

- dos salvillas medianas sobredoradas con esmeraldas.

- una vinajera y campanilla de plata sobredorada.

- siete tazas de plata con sus asas.

- un cofrecito de plata sobredorada.

- un cofrecito con tintero y salvadera de plata.

- un tabernáculo de plata de media tercia con pintura de la Encarnación.

- un Agnus de plata con vidrieras y detrás Sto. Domingo.

- una hechura de Xto. Crucificado de media vara de plata.

- una salvadera y tintero mediano de plata.

- una espada con guarnición de pomo y puño en plata.

- un rosario en los Padre Nuestros de plata.

- cuatro escaparatillos de estrado de caoba y vidrieras de cristal de una vara y tres cuartos.

- un relicario pequeño con pinturas de Ntra. Señora y San Jerónimo.

- un rosario de hombre de plata.

- un medallón de plata sobredorada con la efigie del rey Felipe.

- un relicario de plata y pintado Sta. Teresa y San Antonio.

- una calabaza pequeña de plata sobredorada.

- unas pulseras de perlas.

- una gargantilla de piedras.

- cinco pendientes, una joya y sortijas de oro.

- una Sta. Catalina de oro y diamantes.

- una cruz de oro pequeña con perlas y esmeraldas.

- un angelito con serpiente a los pies, de oro.

- un corderito de perlas en una basa de oro.

- un aguilita de oro pendiente de una cadena.

- una hechura de San Diego de madera, en una cruz de oro y esmeraldas.

- una venera de oro con cerco de esmeraldas de calatrava.

- tres veneras de Santiago, dos de oro y otra de piedra verde.

- una cruz de oro esmaltado.

- un rosario de oro y esmeraldas.

- un rosario de guaiamo de oro.

- diecinueve gramos de perlas. 
- un rosario de coral.

- una crucecita pequeña con tres pendientes de oro y piedras verdes.

- dos laminitas de un tercio ochavadas con reliquias.

- una lámina de tres cuartos de alto de plata de Ntra. Señora. de Paz.

- una lámina con la oración de huerto de un cuarto.

- una lámina de un cuarto con hechura del baño de "Bersabe".

- una lámina de un tercio con hechura de Ntra. Señora y el Niño dormido.

- dos escritorios de Salamanca.

- cuatro escritorios de una vara de carei en marfil.

- un escritorio de charol y en su pie una columnita.

- un escritorio de vara y media de palo santo.

- un escritorio de Salamanca sin tapa de vara y media con pie de pino.

- un escritorio de Portugal de una vara de caoba.

- un escritorio en marfil.

- un escritorio de dos tercios con nueve gavetas embutido en carei.

- dos escribanías de dos tercios en carei y marfil.

- dos escribanías de media vara en caoba.

- dos escribanías de media vara en ébano y marfil.

- un bahul de charol de una vara.

- tres bahulitos.

- siete bufetes de siete cuartas de caoba.

- dos bufetes de vara y media de caoba.

- dos bufetes de siete cuartas de marfil.

- un bufete mediano de caoba.

- un bufete de una vara y cuarta en caoba.

- dos bufetes de merendar en caoba.

- dos bufetes de caoba con pies salomónicos.

- un bufete de pino y cuatro de estrado de carei y marfil.

- dos escribanías medianas de ébano.

- un crucifijo de escultura de media vara y otro más pequeño.

- un crucifijo de marfil con su sitial.

- un tabernáculo de una vara con columnas salomónicas y dentro una Sta. Ana de dos tercios y Ntra. Señora y el Niño Jesús, todo en escultura dorada y estofada.

- una imagen de María de los Dolores con su corona de plata de media vara.

- un Cristo a la Columna de un tercio.

- dos San Juanitos de escultura con peanas doradas.

- tres Niños Jesús de escultura con peanas.

- un San Francisco de un tercio de alto en escultura con peana.

- dos santos chiquitos de bronce con peanas sin dorar.

- un Niño Jesús de barro sin dorar, de una vara.

- un Niño Jesús de marfil con peana de marfil de una vara.

- Ntra. Señora de marfil de una tercia, con corona y peana.

- María Santísima con corona de plata, de una tercia.

- un jardín y huerto con imagen de Ntra. Señora sentada. 
- un arcón de madera con dos cerraduras y cuatro cajones, forrado por dentro de dos varas de ancho y una de alto.

- un cofre bueno de una vara de largo y media de alto forrado de tafetán.

- una papelera de cedro de siete cuartas.

- dos arcos de pino y tres de hierro.

- seis escaparates grandes de dos varas de caoba.

- cuatro cofres grandes.

- un reloj grande de campana péndulo real y caja para piezas.

- un reloj grande de campana más ordinario.

- un reloj con un hombre de bronce, de media vara.

- un reloj para faldriquera con caja de carei claveteada.

- treinta y cinco sillas, dieciocho taburetes de junco inglés.

- una cama de colgar de madera, trece canceles y cinco puertas de vidrios.

- un tablerito de Portugal labrado, para jugar a las damas.

- un bateau de una vara, hecho en Indias.

- seis bateas de diferentes tamaños.

- seis tarimas de pino de Flandes.

- cinco espejos y uno de ébano.

- una alfombra grande de estrado.

- cuatro tapetes y varias colgaduras, almohadas, corredorcillos, colchas, colchones y cortinas.

- varias basquiñas, casacas, mantillas, todo de lienzo de bramante de Portugal y galones de oro.

- trastos de cocina.

- ciento veintinueve libros.

- un cuadro grande de tres varas por dos de ancho con moldura de juguete dorada con Sta. María de la Soledad.

- un lienzo de Sto. Cristo Crucificado y la Virgen y San Juan de dos varas y media de largo por una y media de ancho con moldura de juguete dorada.

- un cuadro de tres varas de ancho de un Eccehomo postrándose ante Pilatos y el pueblo y Barrabás con moldura de madera.

- otro Eccehomo de medio cuerpo pintado en lienzo como de tres cuartos con moldura de juguete dorada.

- dos medios cuerpos de Jesús y María de tres cuartos, con sus molduras doradas.

- dos láminas, una de Ntra. Señora y otra de S. José..

- un Eccehomo de siete cuartos, con moldura de madera llana.

- una laminita pequeña de un Eccehomo y moldura negra.

- un retablo de charol con sus puertas de dos tercios de alto y con la pintura de un Eccehomo.

- doce laminitas en cobre con molduras de ébano, todas de una vara echadas: Cristo a la Columna, Adoración de los reyes, Sta. Ana con la Virgen y el Niño, Huida a Egipto, las Tres Caídas, el Descendimiento de la cruz, Ntra. Señora con su Santísimo Hijo, Ntra. Señora y diferentes niños, Ntra. Señora y algunos Apóstoles, Oración en el Huerto y degollación de San Juan Bautista, Sta. Ana la Virgen y el Niño.. 
doce láminas de cobre y molduras de ébano de una vara echados: Ntra. Señora el Niño y San José, Desposorio de Sta. Catalina, Nuestro Salvador en casa de Marta y María, tránsito de la Magdalena con su gloria de ángeles, triunfo de David con la cabeza de Goliat, juicio de Salomón, una marina profana, otra marina con navíos, una marina con hombres y ninfas en el mar, otro país con figuras pequeñas, una batalla, San Jerónimo en un círculo de flores.

- San Jerónimo de tres varas y cuarta por dos de ancho, con moldura teñida de negro y cuentas doradas.

- dos pinturas de San Jerónimo de un tercio en cobre.

- un San Jerónimo escribiendo de un tercio, en cobre.

- San Jerónimo en el desierto de media vara.

- San Jerónimo de una vara con moldura negra y lisa.

- Jacobo y Raquel en el pozo con molduras de juguete sin dorar.

- el rey Salomón y la reina de Saba de siete cuartas, con moldura antigua dorada.

- un lienzo de Sto. Domingo de vara y cuarta con moldura antigua llana y dorada.

- Cristo Resucitado y diferentes figuras coronándole con moldura antigua dorada, de vara y media.

- en tabla Ntra. Señora y el Niño de vara y media con moldura llana y pintada.

- una lámina en cobre de una vara de alto con un San Agustín con moldura de ébano labrada.

- una lámina de vara y cuarto de Sta. Ana, la Virgen y el Niño.

- una lámina en cobre de un tercio con un Eccehomo y moldura en ébano.

- una lámina en cobre de un tercio con moldura de madera con Ntra. Madre y Señora del Pópulo.

- Sta. María Magdalena penitente de media tercia.

- una lámina de un cuarto de la misma Santa con vidriera y una moldurita en marfil.

- una pintura de San Pedro Apóstol en cobre de una tercia de alto.

- una lámina en cobre hechura en óvalo con Ntra. Señora..

- dos láminas de cobre de un cuarto con moldura negra de Ntro. Señor Resucitado..

- una lámina en cobre de un tercio con moldura negra con Ntra. Señora.

- una laminita en cobre del mismo tamaño de un Apóstol en óvalo de flores.

- otra igual de S. Juan Bautista sobre chapa de cobre una lámina en cobre de un tercio, con el Salvador en la cruz.

- una cuadro de vara y media echado del profeta con moldura blanca.

- la cabeza del Bautista en tabla con moldura negra.

- una lámina en cobre de una vara pintura de Ntra. Señora con moldura llana, lisa y dorada.

- una lámina en piedra pintada de la Oración en el Huerto, ochavada con moldura de carei.

- otra de un tercio, echada, en piedra de la Adoración de los Magos.

- un cuadro de media vara con un Crucifijo de moldura llana.

- una lámina de cobre de un Eccehomo de media vara y moldura de ébano.

- tres laminitas de un tercio en cobre con el Ángel de la Guarda, San Fco. de Paula y San Pablo.

- la cabeza de San Pedro, en media vara y moldura de ébano.

- Adán y Eva en el Paraíso, de media vara, sobre cobre.

- Cristo Nazareno de media vara, sobre cobre. 
- un cuadro sobre tabla de San José de tres cuartas echado, con moldura ordinaria.

- dos láminas en cobre con molduras de ébano con Ntra. Señora y San Antonio.

- una pintura en lienzo de vara y media con Nuestra Señora y Nuestra Señora de Belem.

- un lienzo de una vara de Ntra. Señora, su hijo, San José y San Juanito.

- Jesús dormido en la cruz, de tres cuartos de vara.

- Ntra. Señora con el Niño, de tres cuartos de vara con moldura de juguete.

- un retablito de ébano de dos tercios de Ntra Señora del Pópulo con vidrieras.

- una lámina de una vara echada con moldura de ébano y pintada en cobre la cabeza de San Juan Bautista.

- la coronación de espinas de una vara y media sin molduras.

- un cuadro en lienzo de la devoción de María Santísima y el Niño Jesús y San Juan con moldura llana.

- una laminita de tres cuartos de la Purísima Concepción en relieve, con moldura de cuentas doradas.

- Sta. María, el Niño y San José de tres cuartos de vara con moldura dorada.

- San José enfermo en cama de media vara con moldura de pastas doradas.

- Jesús Nazareno camino al calvario de una vara y media, moldura dorada.

- dos pinturas en lienzo de Sta. Justa y Rufina de tres cuartos de vara y moldura dorada.

- diez láminas de un cuarto y media vara.

- una pintura en tabla de la Sena de una vara con moldura antigua y dorada.

- Sta. María de Belem en un medio círculo con moldura dorada antigua.

- una lámina en cobre de un tercio pintada de San Lucas con moldura negra.

- dos tablas medianas con las Tres Caídas y el Triunfo de la Sta. Cruz.

- una lámina de media vara con San Pedro en su vidriera y reliquias embutidas.

- una lámina en cobre de un tercio, con un anacoreta.

- un cuadro en lienzo del Tránsito de San Francisco de tres cuartos de vara y moldura negra.

- una lámina de piedra de un tercio, de Ntra. Señora, el Niño y San José.

- cuatro láminas de media vara de alto y en forma de medio punto, con la Cruz a cuestas, Descendimiento, Cristo Crucificado de un cuarto de vara con molduras de caoba.

- dos laminitas en tabla con Sta. Catalina y Sta. María de un tercio de vara con molduras de ébano.

- una lámina de media vara pintada de buena mano de la Purísima Concepción con moldura de caoba embutida.

- otra igual de la Adoración de los Reyes.

- un cuadro de una vara con moldura negra de Cristo Crucificado.

- un cuadro redondo de una vara y media de alto con moldura de juguete dorada de un Crucificado dentro de un corazón.

- una lámina de tres cuartos de vara en cobre, de buena mano, de Ntra. Señora y dos Niños.

- un lienzo de una vara de San Juan, con moldurita llana y negra y filetes dorados.

- una lámina redonda de un tercio, en piedra con Ntra. Señora.

- una lámina echada de media vara de la Sena.

- La Asunción, de media vara.

- la Coronación de Espinas, de dos tercios de vara, y moldura negra.

- un lienzo de la Magdalena de un tercio de vara moldura negra. 
- una laminita de cobre de un tercio de vara de Ntra. Señora y San José.

- una laminita de igual tamaño del Prendimiento del Salvador con moldura lisa y dorada.

- un lienzo de Cristo Crucificado de una vara con moldura llana.

- dos láminas de un tercio con sus vidrieras y dentro de ellas flores.

- trece laminitas de un cuarto de vara todas en cobre con molduras de ébano : San Ignacio y San Francisco Javier, San Francisco, San Juan Bautista, San Pedro, Verónica, Nacimiento, San José, Sta. Catalina y la Magdalena.

- una lámina de tres cuartos de vara en cobre de los Santos países y moldura en ébano.

- dos láminas en tabla medianas de Ntra. Señora y San Juan de Dios y Sta. Irene de molduras doradas.

- un cuadro de dos varas del Juicio Final con moldura llana.

- una pintura en tabla de la Dolorosa de medio cuerpo con moldura lisa.

- un lienzo de medio cuerpo del Salvador con marco de bronce del Divino Morales.

- dos láminas de media vara de cobre con Cristo a la Columna y Ntra. Señora, con molduras de ébano.

- dos láminas de media vara de cobre y ébano.

- dos láminas echadas de media vara con molduras de ébano del Sena y un país.

- una lámina en tabla de tres cuartos con moldura de juguete sin dorar de un Crucifijo.

- dos láminas en cobre de un cuarto de vara de un Crucifijo y Ntra. Señora.

- una lámina de media vara de chapa de bronce y esculpida la Purísima Concepción.

- dos láminas de cobre iguales de media vara con molduras negras con Jesús Nazareno y Ntra. Señora.

- una lámina de un tercio de vara de la Oración en el Huerto con moldura de carei y caoba.

- dos láminas del mismo tamaño de cobre con molduras negras con Ntra. Señora y el Niño.

- un cuadro en lienzo muy maltratado sin moldura de tres cuartos de vara y la pintura de Ntra. Señora.

- un cuadrito en tabla de una cabeza de Ntra. Señora de media vara con moldura negra y cuentas doradas.

- dos cuadros de tres cuartos de vara en lienzo de S. Francisco y una Virgen.

- un Apostolado de cuerpo entero en cuadro de a dos varas y molduras de madera blanca.

- un lienzo de vara y media pintado un hombre con un canasto de frutas con molduras sin dorar.

- cuatro cuadritos de media vara sobre la cabeza de un Apóstol.

- un cuadro del mismo tamaño de un país y en él, Cristo curando a los enfermos con moldura negra.

- un cuadro de Sto. Domingo, con vidriera y cortina.

- una laminita en tabla de un tercio de vara con moldura dorada, pintura de San Antonio.

- dos láminas relicarios de flores, con vidrieras.

- siete láminas de cobre como de una vara echadas con la Samaritana, países y diferentes santos, ermitaños y anacoretas.

- dos pinturas en lienzo iguales, de vara y media.

- una lámina de la Verónica de tres cuartos de vara.

- un cuadro de una vara sobre Moisés en el desierto con moldura sin dorar.

- un lienzo de Ntra. Señora de medio cuerpo con moldura de juguete dorada. 
- un lienzo de una vara pintado en tabla del príncipe de Portugal, con moldura antigua dorada.

- un cuadro de dos varas con la entrada de San Felipe en Lisboa.

- un retrato de Carlos de Borgoña.

- un clérigo de medio cuerpo, y en la espalda dice original de Tiziano.

- dos nacimientos de figuras de marfil pequeñas.

- cuatro laminitas de media vara echadas, son ruinas de ciudades.

- dos laminitas en piedra pequeñas: el faraón anegado en el mar Bermejo, una ochavada de moldura de carei y la otra con moldura negra.

- una laminita en cobre como de a tercia echada con moldura de ébano labrada y pintada una Ninfa y otras figuras desnudas y dicen ser original de buena mano.

- una copia de la anterior.

- dos laminitas como de media vara una en cobre y otra en tabla, ambas de Hércules.

- tres laminitas en tabla de una vara echadas con molduras en ébano: tres figuras en una gruta, país de cacería y una partida de naipes.

- dos láminas en cobre de tres cuartos de vara con pájaros y cacería.

- dos tablas de media vara con una marina con niños y peces y otra en forma redonda con molduras blancas.

- del mismo tamaño, un hombre tomando una pipa de tabaco.

- dos láminas pequeñas en cobre con unos ratoncillos y navíos, en redondo.

- dos láminas de media vara de Hércules.

- dos láminas de un cuarto de vara en bronce con una marina y barcos.

- una lámina de cobre de un cuarto de vara con molinos al viento.

- un cuadro de dos varas en lienzo de una mujer que dicen ser Venus desnuda y acostada con moldura en negro y cortina encarnada de tafetán.

- un lienzo de vara y media sin moldura pintada de otra Venus.

- dos tablas de media vara flamencas con figuras.

- tres láminas de un tercio en tabla y bronce con navíos.

- cuatro láminas de países de campo llanos.

- dos laminitas con sus vidrieras iguales de media vara con países de batallas.

- una lámina en cobre de un cuarto de vara con pájaros y fruta.

- un lienzo de una vara sin moldura de la reina soberana.

- un cuadro de más de una vara con moldura de juguetes dorada y estofada con las armas de la casa.

- una pintura de fábula.

- un frutero de tres cuartos de vara, echado.

- una tabla de vara y media con una mujer con frutos y verduras.

- un cuadro de media vara de pintura profana con una mujer matándose.

- un lienzo de un país de campo de dos varas con moldura sin dorar.

- un país con musas de comida de una vara.

- un país en lienzo de una marina de una vara con moldura dorada.

- una pintura en tabla de tres cuartos de vara de Cristo en la Cruz sin expirar, con moldura negra.

- dos láminas de media vara echadas, con pinturas de países en cobre con molduras de madera. 
- tres láminas de cobre de un tercio de vara pintadas con países, marinas y árboles.

- tres láminas de media vara con pájaros y barcos.

- tres láminas de un tercio de vara con países de marinas y campos.

- dos láminas en cobre de un frutero y florero de media vara de alto y molduras en blanco.

- tres láminas de media vara con molduras muy antiguas con molinos al viento y marinas.

- un lienzo de media vara de una cara de mujer con una cofia en la cabeza.

- dos muñecas de mujer de media vara y se les da cuerda como a un reloj y bailan.

- un leoncillo de bronce de media vara de largo y está echado.

- cuatro leoncillos de bronce.

- tres animalitos de bronce.

- cuatro planchas de castaño de nueve varas.

- cuatro escaleras de pasos.

- una esclava negra de cuarenta años..

A.P.N.S. Ofc.1 año 1724 fol.692 y ss.

\section{Documento 3.}

Inventario de los bienes pertenecientes al señor Jerónimo Ortiz de Sandoval y Zúñiga, conde de Mejorada, tras su muerte. Realiza el inventario, su yerno Luis Ortiz de Sandoval con fecha de 17 de Septiembre de 1721, poco después de la muerte del finado.

- doce sillas de baqueta de moscovia y clavos grandes dorados.

- doce sillas del mismo genero de mediadas.

- tres bufetes grandes de caoba bien tratados con sus herrajes.

- un escritorio de Salamanca.

- un escritorio grande de tapa bueno.

- un coche carrocín verde y viejo pero corriente de uso.

- otro coche que llaman tumbón de baquetas con todos sus pertrechos.

- cinco mulas de coche rojas con seis guarniciones.

- dos papeleritas de Indias embutidas en carei y marfil.

- un bufete de cajones.

- un arca grande de madera de caoba.

- un escaparate grande de dos cuerpos.

- dos escritorios viejos de carei.

- un espejo grande de hechura ochavada con moldura de ébano y bufete de caoba.

- dos escaparatillos con loza de China.

- siete canceles de buen porte, viejos azul y blancos.

- ornamentos del oratorio.

- una espada.

- una vela para el patio.

- dos relojes pequeños de faldriquera.

- un bufetillo mediano forrado de terciopelo.

- tres velones de azofar medianos.

- veintiún esteras de esparto. 
- dos bufetillos ordinarios medianos y viejos.

- un espejo grande ochavado con moldura negra de ébano.

- una cama de colgar.

- una colgadura de damasco azul y vieja.

- dos escritorios viejos y otros dos de carei y marfil.

- dos papeleritas de cedro.

- cuatro bahules bien tratados para guardar ropa.

- dos bufetillos de estrado forrados en terciopelo.

- tres lienzos de pinturas grandes con la Oración del Huerto, Ntra. Señora de Belem y San Juan Evangelista con molduras de juguete.

- una sobremesa de hierro con el escudo de armas de la casa.

- una papelerita de ébano y marfil vieja.

- una tapicería de paños de ante que se compone de seis paños y está de media vida.

- otra tapicería del mismo género y seis paños viejos de poca caída.

- doce paños de corte muy grandes.

- ocho tapetes.

- dieciséis lienzos viejos, sin marca. Pinturas de emperadores.

- dos láminas una de Ntra Señora y otra de Sta. Catalina de Siena.

- dos lienzos grandes que son retrato de las personas de la casa.

- diez cuadros de tres varas de largo de diferentes pinturas viejas.

- cuatro lienzos de dos varas con pintura de Ntra. Señora de la Granada, la Soledad, Virgen de la Regla y del Carmen.

- dos pinturas en tabla con molduras de carei de una vara con la Visitación y San Jerónimo.

- dos lienzos muy viejos sin marcos de San Jerónimo y San Francisco de Paula.

- siete lienzos de dos varas de pintura profana.

- un emperador romano, de dos varas.

- la cabeza del Bautista de una vara y media.

- Ntra. Señora de Belem, de una vara, viejo y sin moldura.

- un San Jerónimo de una vara con moldura.

- un lienzo de una vara de un Niño Jesús de buena pintura, con moldura de ébano.

- dos pinturas de una vara y cuarto con la cabeza del Bautista y Ntra Señora de Belem.

- dos pinturas de San Juan Bautista y San Sebastián de tres cuartos de vara.

- Sta. Catalina de Siena, muy viejo y sin marco.

- dos láminas de cobre con una Señora de la rosa y una Ntra Señora de medio cuerpo.

- una lámina de Ntra. Señora de Belem de tres cuartos de vara con moldura dorada.

- trece países muy viejos de una vara, echados.

- dos países y una fábula, todos ellos muy viejos.

- dos cajetas de plata sobredorada muy usadas, para tabaco.

- un tintero, una salvadera y un sello de las armas, todo en plata.

- dos sortijas de láminas de oro con esmeraldas y seis diamantes.

- un vasito y una salvilla de plata sobredorada.

- dos tumbagas finas y un brazalete y un rosario de oro.

- catorce platos de peltre.

- una colgadura de catre de granilla, bordada de cordoncillo.

- seis colchones de lana de diferentes tamaños. 
- ocho sábanas grandes y ocho almohadas blancas usadas.

- tres colchas, nueve cortinas, una estera, siete puertas de vidriera, dos postigos y una ventana.

- un brasero con su sarteneja y badil de metal.

- un pilón de madera de Indias para vender cacao y canela.

- un cofre viejo y grande con tres llaves.

- un arca grande de madera de nogal.

- un escaparate de madera pequeño.

- un bufetillo de pino.

- un espejo mediano cuadrilongo sin pie con hechura de ébano.

- dieciocho vidrios cristalinos de varios tamaños.

- dos faroles viejos.

- una arquita pequeña de tres cuartos de largo.

- tres cobertores, tres tablas de manteles, ocho servilletas, un chocolatero, olla, perol, tinajas, arados, carretillas, calderas.

- utensilios de labranza en la casa utilizada para tal fin.

A.P.N.S. Ofc.1 año 1721 fol.671-673 v.

\section{Documento 4.}

Inventario de los bienes pertenecientes a Lorenzo Pablo de Eceiza, comendador de Pozuelos por la orden de calatrava, y marqués de Villaverde con fecha de 10 de Octubre de 1720. Descripción de sus bienes correspondientes a la hacienda llamada de la Concepción, en el término de la villa de Utrera, para repartirlos entre sus hijos.

(...)

- una cerca a la entrada con caballerizas y pajar y junto su cochera y para entrar tiene su puerta grande con un campanario encima y a la mano izquierda un cuarto alto y bajo pequeños y junto a ellos la capilla bien adornada y junto los cuartos principales con comedores y galerías bajos y altos con sus separaciones para dormitorios, sus cocinas bajas y altas y patios de servicio con lavaderos, su escalera principal y más adelante su molino de aceite con su torre y mirador. Y más adelante un portal que da entrada a los cuartos pequeños y a la bodega y un patio principal con su piso y frente el jardín cerrado de tapias. En el primer patio, cuadra caballeriza y cochera. A la izquierda un cuarto bajo y alto y una galería con oratorio y tres viviendas bajas y dos despensas y un lavadero y su cocina baja y una escalera principal y en la vivienda alta, lo mismo que en la baja, y dos despensas y un comedor que mira a la viña y una ventana para tomar la comida de la cocina alta en un comedor como tribunas para oír misa las señoras. En la misma línea una cuadra de molino con sus trojes y piedras y caldera para calentar el agua, un cuarto del capataz, una bodega, una tarazana de dos naves, un horno, un colgadizo al primer patio y entre la puerta principal, sobre la derecha una escalera hacia el granero ....... 
$\ldots$ en el oratorio $\ldots \ldots \ldots \ldots \ldots \ldots \ldots \ldots \ldots \ldots \ldots$

- un retablo dorado y estofado con la imagen en talla de la Concepción con vestido y corona de plata grande en medio del retablo y a los lados otras hechuras en talla como San José con el Niño, el Santo con su diadema, vara y racimo de azucenas de plata, un Niño con sus potencias y encima de la Virgen, otra hechura de Señor San Miguel dorada y estofada . . .

- una campana de metal para llamar a misa ................

- un escaparate de cedro y pino de dos varas con sus gavetas y sus puertas con cerraduras, llaves y cerrajas en la sacristía . . . . . . . . . .

- ocho cornucopias de metal para poner las velas en el altar, cuatro candeleros de palo dorado y encarnado, una cruz de madera, una campanita de metal, un ara, unas vinajeras de vidrio, un atril, un misal, cuatro tablitas, dos frontales, un velo de gasa de la Virgen y unos manteles de tafetán

- dieciocho cuadros de diferentes devociones de dos varas de largo cada uno

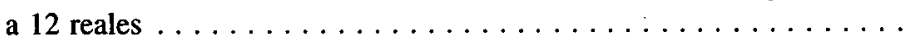

- trece lienzos del Apostolado . . . . . . . . . . . . . . .

- once sillas de baqueta $\ldots \ldots \ldots \ldots \ldots \ldots \ldots \ldots \ldots \ldots$

- una caja de madera de cedro ochavada de una vara $\ldots \ldots \ldots \ldots \ldots$

- tres bufetillos . . ........................

- una papelera de cedro de una vara con pie . . . . . . . . . . .

- un medio escaparate con gavetas y puertas pintado ...........

- un alcarrasero de pino de dos tablas . . . . . . . . . . . .

- un cuadro del Crucifijo y otro de la Concepción . . . . . . . . . .

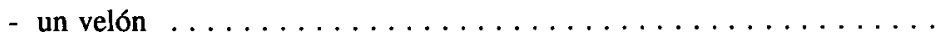

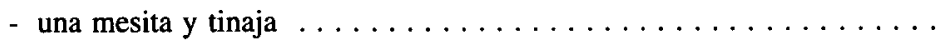

- tres tarimas viejas $\ldots \ldots \ldots \ldots \ldots \ldots \ldots \ldots \ldots \ldots \ldots \ldots \ldots$

- un catre granadillo bronceado con imagen de la Concepción en metal

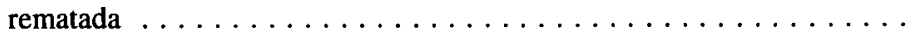

- dos bancos de pino ......................

- un lienzo de Ntra. Señora de Guadalupe y otro de un país . . . . . . . .

- un lienzo de Ntra. Señora de los Reyes de dos varas . . . . . . . . .

- tres armas de camas de viento de pino $\ldots \ldots \ldots \ldots \ldots \ldots$

- una escalera de pasos vieja $\ldots \ldots \ldots \ldots \ldots \ldots \ldots \ldots \ldots$

- un Eccehomo y Ntra. Señora de los Dolores

A.P.N.S. Ofc.8 año 1720 Fol.1151-1259 v. 
Documento 5.

Juan Dávila, jesuita, realiza el inventario de los bienes de su hermana difunta viuda del conde de Vallermoso, con fecha de 24 de Junio de 1727.

- una cama catre de granadillo bronceado para colgar.

- una cama de campaña de nogal teñido.

- una colgadura de cama de damasco carmesí con cuchillejo de oro.

- una colgadura de cama de gasa de Indias color de fuego, flores de oro y colcha de lo mismo guarnecida con encajes blancos finos.

- una colgadura de cama carmesí y gotera de tela sobre blanco.

- un telliz labrado con sedas de colores de Nápoles.

- una toalla telliz celeste y plata para tapar almohadas.

- doce colchones usados chicos y grandes de los señores y familia.

- veinticuatro sábanas y veintiséis almohadas con encajes; colcha de la India bordada de pajizo sobre blanco .

- cuatro colchas ordinarias y usadas.

- un pajarito pequeño con la cola de rubíes y una esmeralda en el pecho.

- un relicario pequeño con su cadenita de oro.

- doce cucharas y tenedores de plata.

- dos cálices y dos patenas de plata.

- cuatro espejos de media vara de luna con sus molduras y marcos dorados sobre tallas de hoja de cardo.

- cuatro escaparatillos de estrado con vidrieras cristalinas y pies salomónicos.

- dos bufetes grandes de jaspe de media vara de largo y embutidos en caoba.

- cuatro bufetes de caoba de siete cuartos de vara con herrajes.

- un escritorio de ébano y marfil con sus puertas.

- dos escritorios de charol y nácar con pies dorados.

- dos papeleras grandes ordinarias.

- doce sillas de caña de Inglaterra y doce taburetes de lo mismo.

- doce taburetes de estrado con fundas de damasco.

- un escritorio de tapa antigua con pie ordinario.

- dos pajecillos para estrado embutidos en ébano y marfil.

- un crucifijo pequeño de marfil con cantoneras de plata.

- un crucifijo de dos tercias de alto con la Santa Cruz toscana.

- una imagen de talla de la Concepción.

- dos Niños de Nápoles con sus peanas doradas.

- un lienzo pintura de Cristo amarrado a la Columna.

- un Apostolado de medio cuerpo muy viejo.

- un lienzo de pintura ordinaria de Ntra. Señora del Pópulo.

- seis lienzos pequeños de pintura frutero.

- ocho países flamencos echados de dos varas de largo.

- un país para sobre puerta de una vara de largo.

- un cuadro de estera de tres varas de pintura de Santiago. 
- un lienzo pequeño echado pintura de Ntra. Señora de la Caridad de San Lúcar.

- un lienzo de Ntra. Señora de los Dolores de una vara y media con moldura antigua.

- dos lienzos de una vara con efigies de la Magdalena y San Francisco.

- un lienzo de dos varas de María Santísima y Señor San José.

- otro mediano de los mismos.

- un Apostolado de medio cuerpo, también muy viejo.

- dos fruteros para sobrepuertas.

- un lienzo pintado con un bodegón.

- un lienzo de San José y otro de San Lorenzo, con molduras de ébano.

- dos esculturas doradas y estofadas de San José y San Antonio.

- un misal romano con su atril, dos albas y dos casullas con flores.

- una colgadura carmesí para los lados del oratorio.

- un frontal de lienzo pintado y unos manteles de altar.

- una alfombra grande acarpetada y bien tratada.

- una colgadura de sala color damasco y brocatel con treinta y seis varas y media de caída.

- una colgadura de paño azul bordado con las armas Dávila y Medina.

- una prensa para prensar ropa de mesa.

- un escritorio de puertas con las armas Dávila.

- un coche carrocín corriente.

- dos mulas del coche con dos guarniciones.

- dos escaños de madera de caoba bien tratados.

- doce canceles buenos para patio y corredores.

- un bufete forrado en bayeta ordinario y viejo.

- un biombo bueno, pintado.

- una escribanía mediana de ébano.

- dos cajoncitos de madera con vidrieras.

- dos tablas de manteles muy grandes y finas.

- doce servilletas buenas y usadas.

- una petaca grande de Indias.

- unas esteras de esparto para esterar nueve piezas.

- un tintero, salvadera y caja de peltre.

- veinticuatro laminitas pequeñas con sus molduritas para el oratorio.

- una sobremesa de damasco carmesí con cenefa de brocatel usado.

- un guardapiés de damasco verde, bien tratado.

- (ropa de hombre y mujer).

- una escopeta grande y un par de pistolas.

- una espada y daga.

- (trastos de cocina).

- Una hacienda de campo en Salteras y otra en Alcalá de Guadaira con los pertrechos de labranza y trastos de cocina.

A.P.N.S. Ofc.1 año 1727 Fol. 444r-446v. 
Documento 6.

Inventario de los bienes de la viuda del conde de Vallermoso, Lorenzo Dávila y Medina, realizado en 1731.

Debido a lo reiterativo del documento con relación al transcrito anteriormente, solamente incluimos los bienes que no coinciden con el referido documento 5 , y aquellas novedades, como son los que se venden tras su muerte y el precio en el que son tasados.

- seis casas en San Lúcar de Barrameda en la calle Bolsa

- una salina en la ría de dicha ciudad ,término de Almonte

- un molino en San Juan del Puerto

- un tributo de seiscientos ducados sobre diversas casas en San Lúcar

- un juro de mil ducados de renta sobre las alcabalas reales de esta ciudad

- un juro de novecientos ocho reales y veinte maravedíes

- un crédito de varios reales que dio al consulado de Sevilla

. . tras su muerte, fueron vendidos los siguientes objetos: . . . . . . . .

- alhajas . .........................

$9110 \mathrm{r}$

- oratorio portátil, colgaduras, doselito, hechura de Cristo Crucificado talla de Nápoles, Niño Jesús y San Juanito, San José y San Antonio en escultura, misal, cajones con vidrieras, dos albas, dos casullas, un frontal de lienzo pintado, manteles de altar, un dosel de damasco, dos sillas, doce almohadas, varios taburetes, una cama, escritorios.(todos los muebles) . . . . . . . .

- un lienzo de Cristo amarrado a la Columna . . . . . . . . . . . . .

- seis lienzos fruteros $\ldots \ldots \ldots \ldots \ldots \ldots \ldots \ldots \ldots \ldots \ldots$

- ocho lienzos de países . . . . . . . . . . . . . . . .

$180 \mathrm{r}$.

- un lienzo echado del Apóstol Santiago . . . . . . . . . . . . .

$40 \mathrm{r}$.

- un lienzo de Ntra. Señora de los Dolores . . . . . . . . . . . . . . . .

- un lienzo de Ntra. Señora y San José $\ldots \ldots \ldots \ldots \ldots \ldots \ldots$

- dos lienzos de San José y San Lorenzo . . . . . . . . . . . . . . . .

$90 \mathrm{r}$.

- veinticuatro laminitas . . . . . . . . . . . . . . . . . .

$90 \mathrm{r}$.

- un lienzo del Niño Jesús $\ldots \ldots \ldots \ldots \ldots \ldots \ldots \ldots \ldots$

$37 \mathrm{r}$.

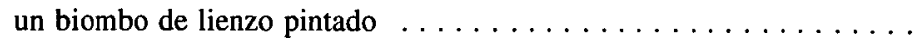

$60 \mathrm{r}$.

una tabla de manteles de 11 varas . . . . . . . . . . . . .

$150 \mathrm{r}$.

- una colcha de Indias, blanca bordada $\ldots \ldots \ldots \ldots \ldots \ldots \ldots$

- doce servilletas . . . . . . . . . . . . . . . . . . . .

$84 \mathrm{r}$.

- sobremesa de damasco carmesí . . . . . . . . . . . . . . .

$45 \mathrm{r}$.

- dos escaparates . . . . . . . . . . . . . . . .

$166 \mathrm{r}$.

- seis esteras de esparto . . . . . . . . . . . . . . . . .

- seis platos de peltre $\ldots \ldots \ldots \ldots \ldots \ldots \ldots \ldots \ldots \ldots \ldots \ldots \ldots . \ldots \ldots$ r.

- una cama de viento ......................... 20 r.

- tres medias tarimas de pino ................. $40 \mathrm{r}$.

- un país sobre puerta pintada una cocinera .............. 67 r.

- cinco lienzos pequeños fruteros . . . . . . . . . . . . . . 150 r. 


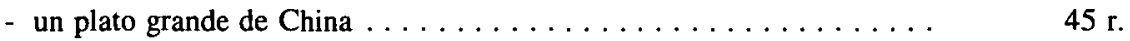

- un chocolatero ........................... $10 \mathrm{r}$.

- una cruz de hierro . . . . . . . . . . . . . . . . 50 r.

- un buey ........................... 350 r.

- elementos de labranza y varias fanegas de trigo . . . . . . . . .

- (ropa)

- un Apostolado . . . . . . . . . . . . . . . . . . . . . 240 r.

- dos lienzos de una vara de la Magdalena y San Francisco . . . . . . . $30 \mathrm{r}$.

- un lienzo grande de Ntra. Señora de la Antigua . . . . . . . . . . . $100 \mathrm{r}$.

- un lienzo de Ntra. Señora de la Caridad ............... $30 \mathrm{r}$.

- dos Apostolados de medio cuerpo . . . . . . . . . . . . . . . . . 480 r.

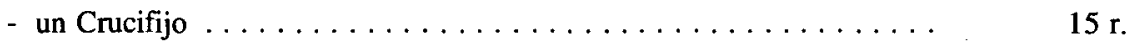

- una imagen de la Concepción en escultura ............... $50 \mathrm{r}$.

- una hechura de Cristo Crucificado de marfil .............. $130 \mathrm{r}$.

- una pintura de Cristo a la Columna ................. $20 \mathrm{r}$.

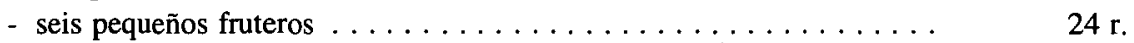

- ocho países grandes con molduras antiguas ............ $180 \mathrm{r}$.

- un lienzo del Apóstol Santiago . . . . . . . . . . . . . . . . 40 r.

- un lienzo de Ntra. Señora de los Dolores . . . . . . . . . . . . 75 r.

- otro de Ntra. Señora y San José . . . . . . . . . . . . . . . . 75 r.

- uno de San José y otro de San Lorenzo . . . . . . . . . . . . . . . . 90 r.

A.P.N.S. Ofc. 1 año 1731 Fol. 500-656 